\title{
BPM-driven Educational Informationization Technology
}

\author{
Xiaohui Gao, Zhiqiang Liu, Yao Zhao, Zhi Chen, Ang Li, Bo Xu, Bo Shen \\ School of Software and Microelectronic \\ Northwestern Polytechnical University \\ Xi'an, China. 710072 \\ E-mail: xubo.nwpu@gmail.com
}

\begin{abstract}
Education informationization is an important part of the reform and development of education. Based on the re-usable and executable "task" and "sub-process" in BPMN elements, a supporting platform for education information system driven by Business Processes is proposed in this paper to meet the characteristics of education information systems: frequent requirement changes and processes cross systems and departments. The platform consists of three parts: a) Custom Processes and Services library; b) Business Process Management Engine; and c) process driven infrastructure that supports the business system. This the Custom Processes and Services library includes education information system oriented custom processes unit library and Custom Service Library; the process driven infrastructure includes Portal Generate Framework and Pages Jump Support Framework. The reusable tasks, sub-processes and services which can be conveniently assembled to processes models to meet the requirements changes frequently, are all collected in Custom Processes and Services library. In order to validate the effectiveness of the platform and technology proposed in this paper, an Advices Collecting System is introduced and designed by the platform and technology. The results show that the supporting platform for education information system driven by Business Processes is an outstanding solution to tackle cross-system integration and frequent requirements changes problems in education information systems.
\end{abstract}

Keywords-Component; Education Informationization; BPMN; MDA; Business Process

\section{INTRODUCTION}

Education infomationization refers to the process of applying information technology to educational sector in an overall and profound manner, aiming at boosting education development and reform. It is an innovative information technology application in the educational domain, and it is considered as strategic option to achieve the goal of enriching human resource and accelerating economic growth. The forestalled awareness of education facilitation though information technology has led to consecutive actions in education reforms and education infomationization, and resulted in the significant achievements in information technology infrastructure construction, combining information technology and curricula, digitalizing course material, computerized management etc.

Education informatization is an important part of education reform and development, though years of development, China still lags far behind in the information technology progress, compared with developed countries. The Chinese government has understood that education infomationization must be upgraded to statecraft level, and making it the substantial driving force in education development.

Infomationization in higher education consists of several dynamic, constant-changing information technology systems, mainly in the aspect of teaching and research, including educational administration, educational information and academic information. Main techniques includes multimedia, networking, intellectualized and digitalized system, with the essential features of opening, sharing, interaction and cooperation.

Infomationization in education brings booming demand for information technology, and due to the constant changing nature, it also presented challenge to corresponding technology that support such system.

To tackle the problems mentioned above, based on Model Driven Architecture (MDA)[2] and Business Process Model and Notation (BPMN) [3], this paper proposed a supporting infrastructure for business process driven education infomationization.

The MDA approach represents and supports everything from requirements to business modeling to technology implementations. By using MDA models, researchers are able to better deal with the complexity of large systems and the interaction and collaboration between organizations, people, hardware, software[2]. Software engineering is currently greatly influenced by MDA[4]. MDA has a potential to increase development productivity and quality by describing important aspects of a solution[5].

BPMN is a typical MDA language which is widely used by many companies. A standard BPMN provides businesses with the capability of understanding their internal business procedures in a graphical notation and give organizations the ability to communicate these procedures in a standard manner.

To build the BPMN \& MDA based infrastructure that supports such systems, this paper analyzed the general requirements and features of education information technology system. Based on that, researchers maximize the BPMN's advantage in business process modeling and management, and build the fundamental model library (FML) and domain service library (DSL) for the education informationization system, to utilize the MDA 's ability in modeling and constructing large system, researchers 
proposed a FML and DSL based rapid application development solution. With this solution, supporting education infomationization systems can be developed in an efficient way, and the solution has been tested in our "Comment Collecting" application.

The remainder of the paper is organized as follows: In Section II, the characteristics of education infomationization system are presented. An overview for BPMN is given in Section III. In Section IV researchers introduced the structure of the process driven IT platform, In Section V, two application modes that are supported by this platform are introduced. In Section VI an application based on the platform is demonstrated. Finally, Section VII contains conclusions as well as some remarks on future work.

\section{ANALYSIS OF THE FEATURES OF EDUCATION INFORMATION SYSTEM}

IT systems for higher education institution are typical IT system with the following feature:

- Fixed role. Roles played in the information technology system includes students, teacher, educational administrators, and the subsidiary service stuff, for extensibility reasons, student parents, superior administrative department as well as the student source, should also be taken into consideration.

- Fixed core business system. Core systems in higher education covers the whole process of education including recruiting, teaching, job opportunities, alumni association, and educational administrative information technology system. The core business system consist of the following: students recruitment system, academic management, teaching management, employment management, alumni relationship management. Administrative information technology system consists of: human resource management, financial management, research management.

- Steady demand for database, basic databases includes student information database, employer information database, educational institution information system, and teach information database.

- Fast-changing business process. Infinite Education reforms pose great demand of upgrading the educational process.

- Complex processes that cross departments and education systems. A great amount of subsystems are built with joint effort from different departments.

\section{STRUCTURE OF BPMN}

BPMN defines a Business Process Diagram (BPD)[7], which is based on a flowcharting technique tailored for creating graphical models of business process operations. A Business Process Model, then, is a network of graphical objects, which are activities (i.e., work) and the flow controls that define their order of performance[3].

BPD composes of four basic categories of elements as follow:

- Flow Objects;
- Connecting Objects;

- Swim lanes;

- Artifacts.

BPDs are executable. An Activity is work that is performed within a Business Process. An Activity can be atomic or non-atomic (compound). The types of Activities that are a part of a Process are: Task, Sub-Process, and Call Activity, which allows the inclusion of re-usable Tasks and Processes in the diagram.

Combining typical features of education information technology system with the high reusability and excitability of the BPMN element "task" and "subprocess", researchers built an education IT system oriented Basic process unit library. Additionally, based on the BPMN engine, a process driven, education oriented framework that can automatically generate and deployment applications has been proposed.

\section{STRUCTURE OF THE BUSINESS PROCESS DRIVEN PLATFORM}

The business process driven IT platform consists of 4 main parts: education information technology system oriented Custom Process and Service Library, Business Process Management Engine, information technology system portal Generate Framework and the Pages Jump Support Framework. As shown in Figure 1

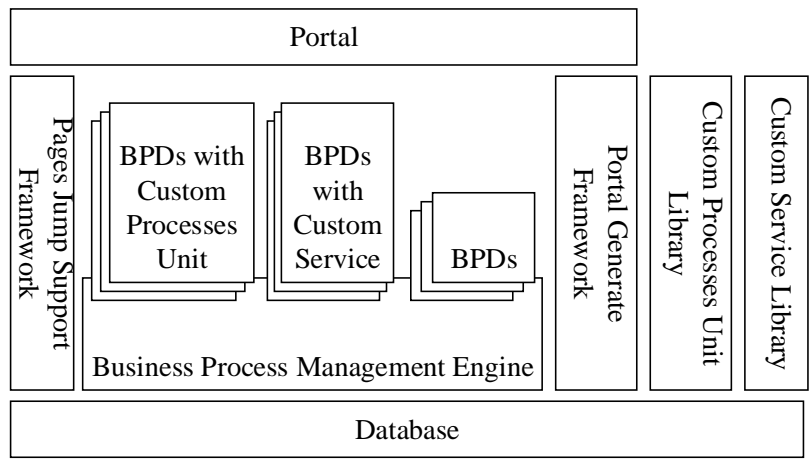

Figure 1. Four part of the platform

BPDs with Custom Processes Unit is deployed on Business Process Management Engine, BPDs with Custom Service and others BPDs, Portal Generate Framework and Pages Jump Support Framework together with Business Process Management Engine support the system, and generate part of the Portal.

\section{A. Custom Processes and Services library}

The original elements "Activity" is unable to accomplish any specific business process without binding to a context, e.g., database operation, access to global/local variables, business logic and the corresponding user interface. Therefore, combining typical features of education information technology system with the high reusability and excitability of the BPMN element "task" and "sub-process", researchers built an education information technology system oriented Basic process unit library, the library includes custom processes unit library and Custom Service Library.

The custom the processes unit library stores process unit for education information technology system, e.g., Course structure, teacher status, credit monitor, these 
custom process unit are built with labeling technique for activities and tasks with general functionalities and thus highly reusable. Each process unit is shipped with database operation function, input/output definition and the context, and is used as the basic building blocks for educational process construction. Process unit provides a higher level modeling technique, and frees user from building process from ground up with basic BPMN notations.

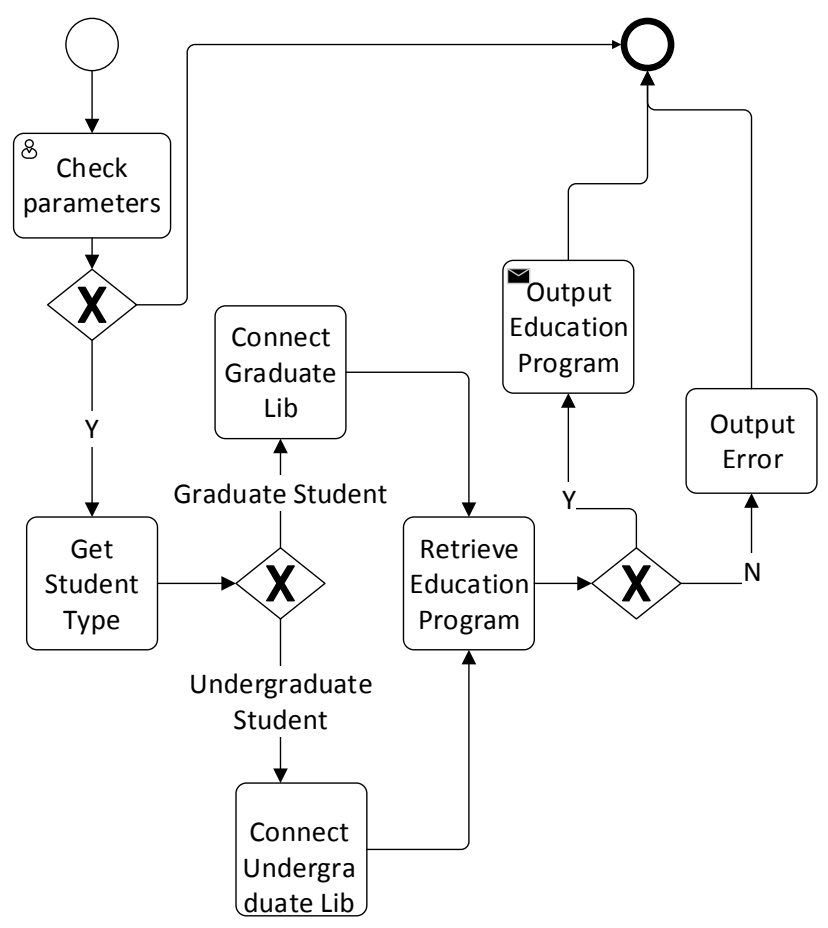

Figure 2. BPD of get education programs

Figure. 2 shows the basic constitution a process unit: "accessing student course plan", in this very unit, student category, course information database, querying method and result format are all included. When put into a live environment with, this process unit will function as define if the access is granted.

\section{B. Process driven supporting system}

One fundamental difference between BPMN and the MDA language (e.g., UML) is that it can be deployed to a certain BPMN engine [8], and run the process with the engine interpreting the BPMN graph. The supporting system for education information technology facilities proposed in this paper includes Portal Generate Framework and Pages Jump Support Framework.

Figure. 3 illustrates the table generated by Portal Generate Framework, and the table is populated with "Sequence", "Type", "ID", "Caption and Action", respectively. As seen on the diagram, portal pages generated by Portal Template are based on the table, by Menu1 triggering BPD2, Menu3 trigger BPD1 and Menu2 joint to the URL specified in Action.

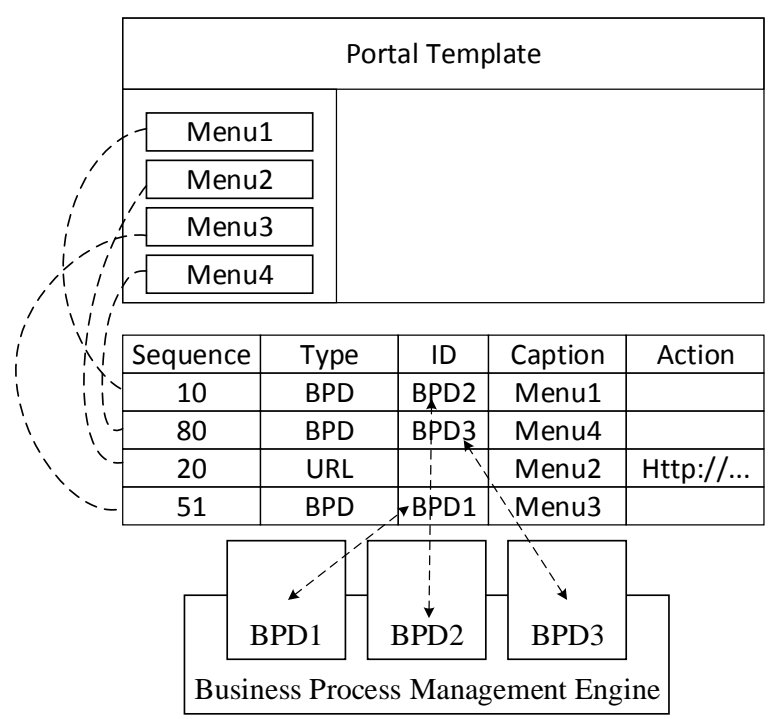

Figure 3. Portal Template

Pages Jump Support Framework determines the next jumping page by each output from BPD activities, or from the configurations of activity, when both results are none, the default page will be used, as seen in Figure. 4

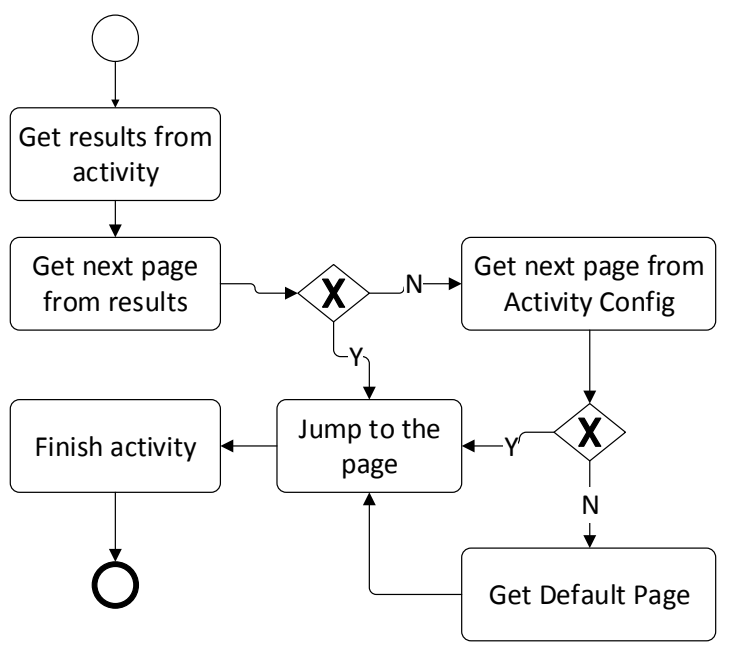

Figure 4. Jump Page

\section{APPLICATION PATTERNS OF THE PLATFORM}

Two patterns of application, one for single system development and one for multi-system integration, are provided:

\section{A. Education information system development}

With the rapid change in the educational progress, the underline information technology architecture that support the information technology system needs to be adaptive, and this requirement is fulfilled in the technology proposed in this paper. The various educational process stored at Custom Processes and Services library can be composed together to build the BPDs that support the education information technology system in a short time. On the process changes, process model can be updated and redeployed to adapt to this changes without source code rewriting. 


\section{B. Education information system integration}

Since in education information system there are a lot of complex cross- different departments and system processes, the need for systems integration and services integrated is urgent. One should think that service integration is standardized with the upcoming of BPMN 2.0, however, BPMN defines surprisingly little about service integration[11]. With the support of Custom Processes and Services library, system integration is made easy.

Based on the platform mentioned above, there are two forms of integration:

- Remote service call. Services in Custom Service Library can not only be used in-system, but also serve as Web Service, i.e., services that can be called from extern systems. For education information technology system Service with port, the library services can be integrated in the form of Web Service.

- Process Insertion. Process Insertion refers to the mutual insertion of processes from difference system, and it allows the direct process call from another system. The BPM engine used in this paper support the Remote Sub-process Call, which enables distributed BPDs deployment on BPM engine.

\section{EXAMPLE APPLICATION}

The usability and performance of the proposed platform are demonstrated with a typical application in education information technology system, the "Comment Collection" application.

Advice Collection is a basic and important application in education information technology system, it is used to collect, manage, store and report comments and suggestions. As independent application, it is also widely used to be integrated into other systems. For example, comments from students are taken into account when evaluating teacher's performance, the "Comment Collection" is used to collect words from students, and then pass on the result to Teaching Evaluation System in a certain format.

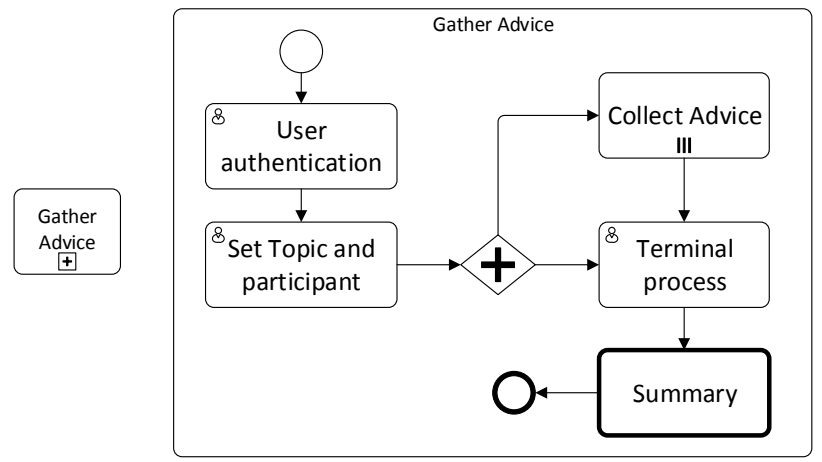

Figure 5. Gather Advice

A simplified model is shown in Figure.5 As an independent system, it is stored as a basic unit in Custom Service Library, in the form of collapsed sub-process.

The "summary" task shown in Figure .5 is a converging point that indicates system integration, and this task needs to be customized based on system on both side.

\section{CONCLUSIONS}

The development of information technology, especially the internet, is pushing for reforms in the education domain at a global scale. To meet the high demand form education information technology systems, this paper proposed a process driven supporting platform based on BPMN and its related technology, and two application modes is provided: system integration and stand along system development.

From our research it can be concluded that, the proposed process driven supporting platform is the best capable solution to support both frequent change systems and cross departments and systems integration. In the future, researchers will work on improving the usability of the platform.

\section{ACKNOWLEDGMENT}

This work was financially supported by Aerospace Supporting Technology Foundation of China under Grant No. 2013-HT-XGD, and National Natural Science Foundation of China under Grant No. 61373120, and the project of National Defense Basic Scientific Research of China, and undergraduate innovation funds of Northwest Polytechnical University, China.

\section{REFERENCES}

[1] Z. Sha, Z. Yi, Y. Hao, and W. Di, "A Comparative Study of Development Strategies for ICT in Basic Education of China, United States and Singapore," Education Research, vol. 20, no. 2, pp. 34-45, 2014.

[2] OMG, "MDA Guide revision 2.0," OMG, 2014.

[3] OMG, "Business Process Model and Notation (BPMN) V2.02," OMG, 2013.

[4] M. Asadi, M. Ravakhah, and R. Ramsin, "An MDA-Based System Development Lifecycle," in Modeling \& Simulation, 2008. AICMS 08. Second Asia International Conference on, Kuala Lumpur, 2008, pp. 836-842.

[5] J. Imen, M. Khemaja, and M. Abed, "Towards MDA implementation based on a novel BPMN metamodel and ATL transformation rules," in 4th International Conference on Logistics (LOGISTIQUA), Hammamet, 2011, pp. 62-67.

[6] W. Di, Y. Xiaorong, L. Chun, and S. Yinghui, "Research on the Indicator System of the Development of Education Informatization," Education Research, vol. 21, no. 1, pp. 92-99, 2014

[7] I. Solichah, M. Hamilton, P. Mursanto, C. Ryan, and M. Perepletchikov, "Exploration on software complexity metrics for business process model and notation," in International Conference on Advanced Computer Science and Information Systems (ICACSIS), Bali, 2013, pp. 31-37.

[8] K. Baina, and S. Baina, "User experience-based evaluation of open source workflow systems: The cases of Bonita, Activiti, jBPM, and Intalio," in 3rd International Symposium ISKO-Maghreb, Marrakech, 2013, pp. 1-8.

[9] H. Jian, Z. Zhiqiang, and L. Zhongnan, "Implementation of Process Management and Control Based on JBPM4.4," in 2011 Second International Conference on Networking and Distributed Computing (ICNDC), Beijing, 2011, pp. 218-221.

[10] W. Yonggui, and L. Haishan, "Application and research of JBPM workflow based on JBoss Seam," in Advanced Computer Control (ICACC), 2010 2nd International Conference on, Shenyang, 2010, pp. $515-518$.

[11] M. Doedt, and B. Steffen, "An Evaluation of Service Integration Approaches of Business Process Management Systems," in 35th Annual IEEE Software Engineering Workshop (SEW), Heraclion, Crete, Greece, 2012, pp. 158-167. 